\title{
CLASSIFICATION OF CAR EMBLEMS
}

\author{
Csaba Dömötör \\ Associate Professor, University of Miskolc, Institute of Machine and Product Design \\ 3515 Miskolc, Miskolc-University, e-mail: machdcs@uni-miskolc.hu
}

\begin{abstract}
This article organizes the motifs found in the logos of the automotive industry representatives and presents their role in the brand image. It covers the differences in meaning between the logo and the emblem, describes the main aspects of the design and presents the messages conveyed by the dominant graphic elements. Categorization is based on the defining symbols of the emblems.
\end{abstract}

Keywords: automotive, logo, emblem, branding

\section{Introduction}

It is crucial for the market position of a company or brand that it is easily recognized by customers or clients or can be distinguished from competitors in the market. An excellent tool for the brand is a clearly identifiable, well-recognizable and memorable unique signal that in this way the brand image of the basic elements can be.

\section{Logo, emblem and symbol}

A sign identifying a brand is most commonly referred to as a logo in common parlance. In many cases these signs do not have the main feature of the original word "logogram", which can be defined that it is a sign representing a word or phrase. But logos can also be word images or signs derived from them. The common feature is that they consist of letters or recall them. The unique signs that are the subject of the article are therefore called emblem, which can be used as a broader term for signs that do not contain real letters, since the emblem is the graphic sign itself. In addition to these concepts, it is worth mentioning the symbols, which also often appear in logos representing the corporate image. The symbol is an (word)-image that visualizes abstract thought content, a specific transmission of meaning, so it is a kind of compact visual message. The purpose of logos is to briefly express the personality or image of a company or brand.

\subsection{Requirements}

The primary goal of for-profit companies is to make a profit by developing products that meet - or promise - consumer needs and can be sold. To do this, a well-designed logo can provide effective support.

Identifiability is the most important of the many requirements, which is most helped by simple but well-recognized motifs. When designing an emblem - as a product -, it is almost always a good choice, regardless of style, to evoke the "always fashionable nature" by adapting a pattern or colour combination, a distinctive formal element, or just a well-established ratio. The organic form components embody the reliability and durability in the viewer 's subconscious. Because these are 
features that most users look for when purchasing a product, so it's a good idea to convey it with the emblem.

It helps to deliver the message we want to deliver easier by following certain requirements during design process. In general, the following requirements can be set for logos:

- Simplicity

- Distinguishability

- Clear message

- Originality

- Proper shape

- Well-selected colours

- A good font type

- Timeless

- Ready to reproduction

- Zoom in / out

\subsection{The meaning of shapes}

For example, while symbols have specific meanings, simpler geometric shapes can usually be assigned more general image associations. Thus, for example, in the automotive industry, the ellipse/oval/circle shape is ordinary, since it carries a positive emotional message. In addition to infinity, the concepts of friendship, connection, love, but also femininity, magic and mystery are associated with it. Another periodically recurring geometric element in car emblems is the shield. The dominant motif of this is the triangle, which is the symbol of excitement, risk and danger, but it can also symbolize the balance and stability. The square and the forms associated with it can be related to the concepts of strength, courage, safety, reliability, professionalism, efficiency. The vertical lines as main motifs radiate masculinity, strength and aggression while the horizontal lines bring a sense of community and calm. A special form is the spiral, which is the embodiment of growth, creativity, serenity and intelligence. The natural forms are generally associated with concepts of the originality, uniformity, balance and freshness. Finally, the abstract forms are used to highlight uniqueness, craftsmanship and sophistication.

\section{Classification car emblems}

Most car manufacturers operate as part of a long-standing group of companies, so in many cases the emblem of a brand has changed several times, following ownership, the market, fashion or even user needs. In most cases, these changes retain the main motifs, but in some cases bring a radically new design. Most of this article processes the current car logos of today, but some - especially in Hungarian-related cases - also look back at the memories of the past.

There are several options for grouping logos, but in our case the main element of form as a dominant motif is the classification aspect. Of course, there are also emblems that can be inserted into two or more types, so they are classified into a separate group. We will continue to follow this basic classification. 


\subsection{Verbal, referring to brand name}

The most obvious way to increase the awareness of a company or brand is to use a real "logogram", which clearly refers to the name in letters. If the designer chooses this path of logo designing, in many cases he or she can only work with a unique colour and font, spatiality, or just an enclosing shape. It is no coincidence that this type is often combined with a characteristic geometric shape.

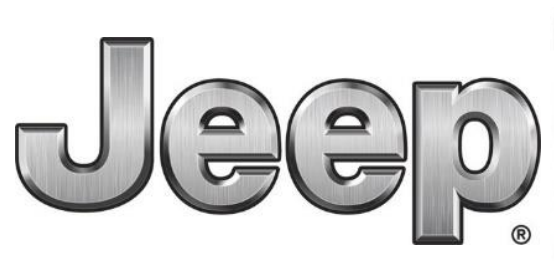

a)

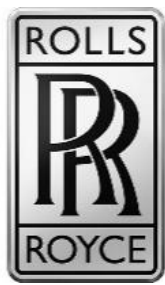

b)

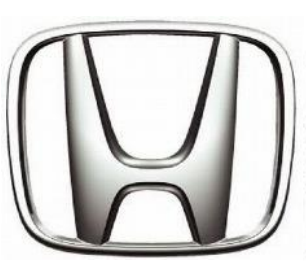

c)

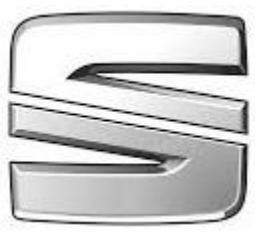

d)

Figure 1. Verbal type logos referring to brand name

From the examples shown in Figure 1, the Jeep logo is pure and practical as the vehicle itself. The Rolls Royce fixed rectangle enclosed logo, which was tagged by additional horizontal lines, transmits reliability, impassibility and peace. The Honda custom designed font type and tapered wedge-shaped initial in the rounded trapezoidal form suggests dynamism as well as the Seat logo, which also shows the brand's stylized initial, but the geometry of sportiness is also emphasized by diagonal line.

\subsection{Abstract geometrical}

By focusing on abstract or geometric forms, even thought content that goes beyond the brand name, reflects the brand image, company philosophy or even refers to the history of the company can be conveyed (Figure 2). In the case of Toyota, for example, the two inner ellipses symbolize trust-based intercourse between the customers and products, while the outer represents the world that demands to meet challenges. But fans of this cars also discover all the characters of the brand name in it [7]. In Mitsubishi's geometric emblem, the Japanese fonetic itself replays the japanese phonymous, as "mitsu" means three and " hishi" means a chestnut species native to the island nation. The word composition of the two means diamond in Japanese, in which, according to the relevant grammar, a "b" is pronounced instead of the " $h "$ in the middle. Evidence of the durability of these three diamondforming symbols is that they have been used in their unchanged form since the founding of the original - not yet automotive - company in 1875 .

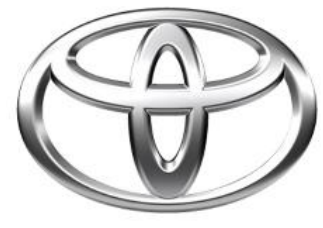

a)

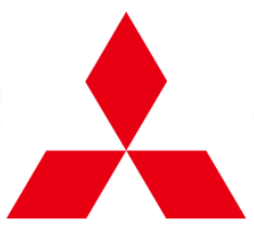

b)

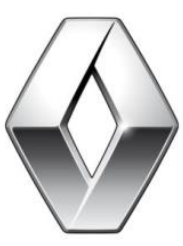

c)

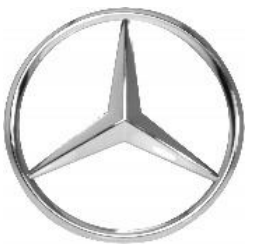

d)

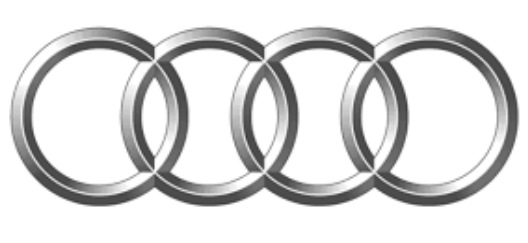

e)

Figure 2. Abstract and geometrical motifs

Similarly, the diamond shape dominates the Renault logo. The original version of which was designed by Hungarian-born painter Victor Vasarely in 1972, based on the diamond motif used as the company's logo from 1925 onwards, which evokes an image of a Möbius ribbon, suggesting a sense of 
infinity. The three-pronged star of Mercedes is one of the most well-known symbols from cars and has symbolized the motorization of the ground, sea and air since the 1910s. Much more prosaic meaning is the four rings in the emblem of Audi. It is a reminiscent of the 1932 fusion of the four major car factories (Audi-Horch-DKW-Wanderer).

\subsection{Evocative}

The evocative type of emblems has much more concrete content because of the various, well known, real shapes, silhouettes or patterns which use simplified geometry (Figure 3). In fact, the hidden meaning is not always clear in these cases either, but in each case it can be said that they are stylizing the shape of a real object and not a complicated concept. One of the most well-known misunderstanding connect to the $\boldsymbol{B} \boldsymbol{M} \boldsymbol{W}$. This emblem was last modified in 2020, but the main graphic basic elements are the same for 100 years, which has the colours and pattern of the Free State of Bavaria blue and white patterned flag indicating, while at the same time it carries on the circular logo of the original company [7]. The rotating aircraft-propeller - which was wrongly mentioned in several sources - was only brought into the public consciousness because of an advertisement in 1929, although it is a fact that the manufacturer did originally produce aircraft engines and that ad referred to this.

In addition to traditional car manufacturers, smaller and larger companies are constantly entering the market, usually trying to thrive in a narrower segment. The most typical is the category of supercars, in which many small companies operate. Tesla Inc., which is the first carmaker among the high-tech companies in Silicon Valley, is an American company that is different from the others. It is also a young business because of the 2003 foundation but it quickly grew giant. The "T" letter on their purely electric vehicles in shaping their logos shows a part of the cross section of the electric motor invented by the Serbian engineer Nikola Tesla. Similarly, a technical solution is recalled by the Citroën emblem, in which the reverse dual V-shape refers to the arrow-toothed gear patent of the founder André Citroën.

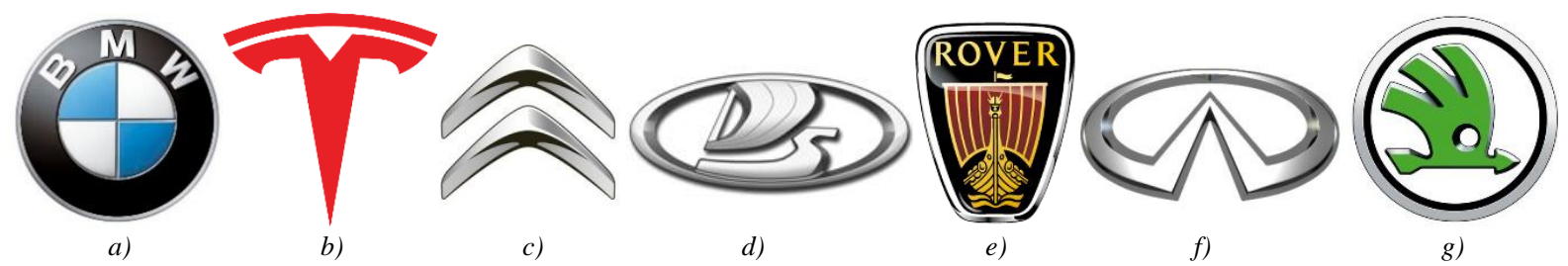

Figure 3. Examples of evocative type car emblems

The old traditions are a reference to the long-distance shipping evocative emblems. An interesting similarity can be observed, as the power of conquest is also embodied in the emblems of the Lada and Rover by a Viking sailing ship. In the case of the first, only a stylized silhouette can be recognized, since the first letter of the original Cyrillic letter VAZ inscription (BA3) was formed into a ship shape. [6]

Reminiscent of long-term use that suggests reliability, the Infiniti logo embodies the stylized letter "I" of the brand name in an ellipse that symbolizes infinity, attaching it to an endless straight road. The $\breve{S} k$ oda emblem which - is not tied to mobility - originally recalled an Indian warrior with a feathered headdress, was later changed to a winged arrow, but in both cases it was intended to symbolise authenticity and successful competition. 


\subsection{Natural}

In the series of car logos using natural motifs there are analogies typically from the fauna, but in the history of the car industry there was also a recurring motif from the characteristic, massive, shiny leaves of the plant, or wreath of laurel branches.

Common examples from the wildlife include wings and birds associated with flight, but horses that have proven themselves in transport also play a prominent role. Manufacturers often use predators, but we also find several examples of mythological creatures. Among the herbivorous animals, motifs referring to ruminants form an even larger set, while the line is closed by the category of crawlers.

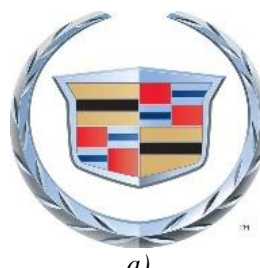

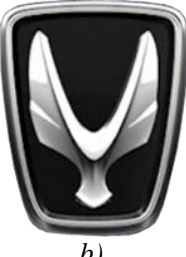

b)

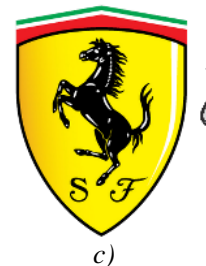

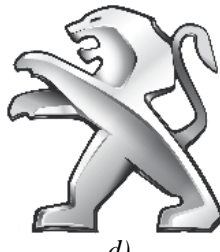

d)

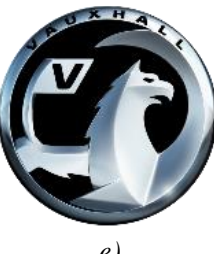

e)
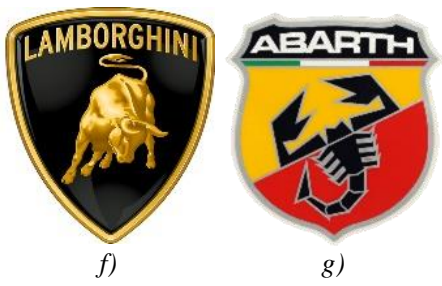

Figure 4. Natural motifs sub categories: a) wreath, b) wings and birds, c) horses, d) predators, e) mythical creatures f) ruminants, $g$ ) crawlers

Although we are now focusing specifically on natural motifs represented by graphic elements, it is worth mentioning that car manufacturers also prefer to choose model names from nature. For example, many Volkswagen cars are named after high streams (Passat, Golf, Bora). In the case of the Renault Kangoo vans the name reminds us to the well-known marsupial animal, but similarly the "small and cute" impression can mounted on a Fiat also by Panda named small city car, although it is named after the travellers' Roman goddess, Empanda.

\subsection{Mixed}

Strictly speaking, the logos bigger part would be classified into this category, as they often combine multiple motifs made such a mark. In most cases, the brand name itself or its initials carry it, or just complement the basic element of form. But we only classify a given emblem into this category if these two or more basic motifs have almost equal emphasis.

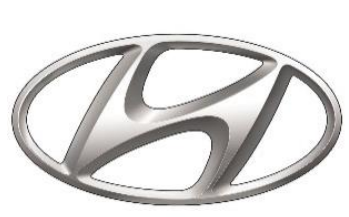

a)

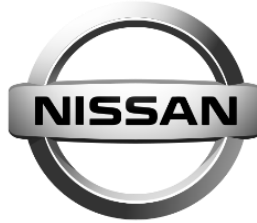

b)

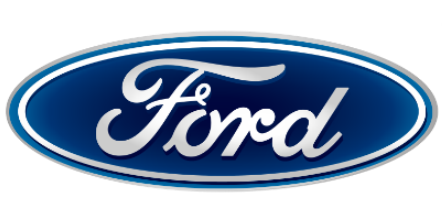

c)

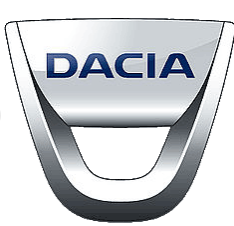

d)

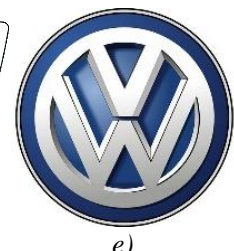

e)

Figure 5. Mixed car logos

In Figure 5 you can see such logos. In the case of Hyundai, in addition to the dominant " $H$ " in the middle and the ellipse that encloses it, there is a truly unrecognizable content. This is the fact that the first letter in the brand moulding middle shape (Figure 5.a) also symbolizes two men shaking hands, indicating a close relationship between the customer and the company [7]. However, this meaning is mostly hidden from the majority, which is why this logo remains in this category. The logos of Nissan, Ford and Dacia presented in Figure 5.b-c-d are also included here because of the same strength of the enclosing shape and the inscription contained therein. The Volkswagen logo is similar 
to this, but it has already succeeded in integrating the initials of the words "Volk" (people) and "Wagen" (car) in such a closed circle that these motifs together form a new unity in which many people no longer notice both letters.

\section{Summary}

The most important task of brand signals is to convey value. Choosing the right motifs assists deliver the message you want, and on the other hand improve the memorability of the emblem. The processing of car emblems will continue and a symbol adapted from nature will be presented in detail in a later article.

\section{Acknowledgments}

The described article was carried out as part of the EFOP-3.6.1-16-2016-00011 "Younger and Renewing University - Innovative Knowledge City - institutional development of the University of Miskolc aiming at intelligent specialisation" project implemented in the framework of the Szechenyi 2020 program. The realization of this project is supported by the European Union, co-financed by the European Social Fund.

\section{Sources}

[1] Simon Heptinstall: Car Marques: A Graphic Guide to Automotive Logos and Emblems, Motorbooks, 2018, ISBN: 0760362457

[2] Alina Wheeler: Designing Brand Identity, John Wiley \& Sons, Inc. 2009, ISBN 0470401422

[3] Kevin Budelmann: Brand Identity Essentials, Rockport Publishers, 2010, ISBN: 1592535781

[4] Orgoványi Gábor: Design és tipográfiai alapok, Tervezőgrafika II. tananyag, 2010 http://centroszet.hu/tananyag/tervgrafika2/212_a_renault_log_trtnete.html

[5] https://listcarbrands.com

[6] Dömötör, Cs., Péter, J.: Természeti elvek az analógia alapú tervezésben, GÉP, Vol. 63, No. 12., ISSN 00168572, Miskolc, 2012. november, pp. 29-32.

[7] https://vancello.blog.hu/2011/07/20/igy_szuletett_a_lada_logo 